\section{O processo de trabalho dos agentes comunitários de saúde: contribuições para o cuidado em territórios rurais remotos na Amazônia, Brasil}

\section{The work process for community health agents: contributions to care in remote rural territories in Amazonia, Brazil}

\author{
El proceso de trabajo de los agentes \\ comunitarios de salud: contribuciones para el \\ cuidado en territorios rurales remotos en la \\ Amazonia, Brasil
}

Juliana Gagno Lima 1,2

Lígia Giovanella 2

Márcia Cristina Rodrigues Fausto 2

Patty Fidelis de Almeida 3 doi: $10.1590 / 0102-311 \times 00247820$

\section{Resumo}

O objetivo do artigo é analisar o processo de trabalho dos agentes comunitários de saúde (ACS) em municípios rurais remotos e identificar especificidades e contribuições para o cuidado na atenção primária à saúde. O estudo qualitativo abrangeu 23 entrevistas com ACS e enfermeiros das equipes de saúde da família em cinco municípios rurais remotos do oeste do Pará, Brasil. A análise do processo de trabalho dos ACS contemplou duas dimensões interligadas: escopo de práticas e qualificação para o trabalho. O escopo de práticas mostrou-se abrangente, envolvendo acompanhamento familiar, cuidados e medidas preventivas individuais, abordagem coletiva e atividades administrativas. As visitas domiciliares constituem a principal ação dos ACS e uma importante forma de contato dos serviços de saúde com os usuários, atendendo a diferentes objetivos de cadastro, cuidado ou informação. Os ACS de localidades rurais remotas, em geral o único recurso de saúde acessível, apresentaram escopo de práticas mais abrangente que os da sede dos municípios, com inclusão de procedimentos individuais. A qualificação dos ACS para o trabalho pode potencializar ou limitar o desenvolvimento de suas práticas e foi expressa por alta motivação dos ACS, insuficiente supervisão e educação permanente e baixa integração com a equipe. São necessárias politicas que reconheçam as especificidades e garantam maior apoio (materiais, transporte e educação permanente) para o pleno desenvolvimento do trabalho do ACS nos municípios rurais remotos amazônicos. O conjunto ampliado de práticas dos Agentes sugere ser este um relevante ator para promover cuidados, facilitar acesso da população à rede de atenção à saúde e um elo real entre populações rurais e serviços de saúde em municípios rurais remotos.

Agentes Comunitários de Saúde; Saúde da População Rural; Atenção Primária à Saúde

\author{
Correspondência \\ J. G. Lima \\ Instituto de Saúde Coletiva, Universidade Federal do Oeste do \\ Pará. \\ Rua Vera Paz s/n, Santarém, PA 68040-470, Brasil. \\ julianagagno@gmail.com \\ 1 Instituto de Saúde Coletiva, Universidade Federal do Oeste do \\ Pará, Santarém, Brasil. \\ 2 Escola Nacional de Saúde Pública Sergio Arouca, Fundação \\ Oswaldo Cruz, Rio de Janeiro, Brasil. \\ 3 Instituto de Saúde Coletiva, Universidade Federal Fluminense, \\ Niterói, Brasil.
}




\section{Introdução}

Em todo o mundo, populações rurais dispõem de menor oferta, utilização e acesso a serviços de saúde e apresentam os piores indicadores de saúde, quando comparadas às populações urbanas 1,2,3,4,5. As desigualdades em populações rurais envolvem: exclusão do direito à proteção à saúde, exclusão social por baixa renda 6 , dificuldades de transportes 2,7 , menor acesso a recursos de informação e comunicação 2,8 e distribuição desigual e insuficiente dos profissionais de saúde, fatores que intensificam as condições desfavoráveis em saúde 4,6.

No Brasil, persistem importantes desigualdades regionais e sociais nas condições de saúde e acesso a serviços, ainda que atenuadas nas últimas décadas pela geração de emprego e renda, políticas de transferência de renda e ampliação da oferta de serviços do Sistema Único de Saúde (SUS) em especial da Estratégia Saúde da Família (ESF) 9,10. Essas desigualdades são mais intensas em áreas rurais remotas. Residir a vida toda em zona rural, além de fatores como gênero, idade, baixa renda ou escolaridade, afetam negativamente a qualidade de vida e saúde da população 11.

Na região amazônica brasileira, desafios estruturais e políticos para a implantação de políticas públicas de saúde são intensificados frente à diversidade regional, com implicações para a organização do sistema de saúde: áreas de cheia e vazante dos rios, alta dispersão populacional, precárias condições de trafegabilidade, presença de populações tradicionais com necessidades específicas, como indígenas, ribeirinhas e quilombolas 12 .

$\mathrm{Na}$ experiência internacional, a melhoria de acesso a serviços de saúde em áreas rurais remotas é preocupação de muitos governos 13,14, com desenvolvimento de estratégias específicas enfatizando componentes comunitários e determinantes sociais na atenção primária à saúde (APS). Dentre esses, há programas de agentes comunitários de saúde (ACS) em diversas modalidades com atuação genérica na promoção e educação em saúde; específica para programas de saúde pública; ou como mediadores comunitários, voluntários ou servidores dos sistemas nacionais de saúde, em especial em países de renda média e baixa. Devido à sua capilaridade e custo relativamente baixo, programas de ACS foram implantados para melhorar a prevenção de doenças e o acesso ao sistema de saúde nesses países 15 , trazendo benefícios à saúde da população 16,17 .

No Brasil, a criação de um programa nacional de ACS (Programa de Agentes Comunitários de Saúde - PACS) data de 1991, ainda que experiências isoladas anteriores ao SUS ocorressem nos estados do Paraná, Mato Grosso do Sul, Ceará, dentre outros 18. O PACS inicialmente implantado em municípios de baixa densidade populacional, com características de seletividade e ênfase em cuidados infantis, orientações sobre hidratação oral, vacinação e desnutrição 19,20,21 foi a partir de 1994 integrado de forma gradual e transitória ao Programa Saúde da Família (PSF). Normativas sobre o trabalho dos ACS fortaleceram a sua atuação no SUS, principalmente na prevenção de doenças, promoção da saúde e identificação de necessidades da população e do território, por meio da visita domiciliar 22,23. Não obstante, inúmeros desafios permaneceram para a qualificação de seu trabalho em áreas urbanas de elevada concentração populacional 19,21,24.

Questionamentos sobre a existência do ACS e suas atribuições foram intensificados, a partir de 2016, e expressos na revisão da Política Nacional de Atenção Básica (PNAB), em 2017, que permite a redução do número de ACS nas equipe ESF e a ausência de ACS nas equipes de atenção básica, agora equiparadas às equipes ESF 25 , com impactos que podem ser ainda mais severos em territórios rurais remotos 26 .

Partindo-se do pressuposto de que os ACS têm um importante papel para a garantia de cuidados em áreas rurais e remotas, territórios de origem de atuação destes trabalhadores da saúde, o objetivo deste artigo é analisar o processo de trabalho dos ACS em municípios rurais remotos do oeste do Pará e identificar as especificidades e contribuições para o cuidado na APS. O processo de trabalho dos ACS enfatizou duas dimensões interligadas: escopo de práticas e qualificação. 


\section{Metodologia}

É um estudo qualitativo, que compõe a pesquisa nacional com estudo de casos múltiplos de 27 municípios rurais remotos conforme classificação do Instituto Brasileiro de Geografia e Estatística (IBGE, 2017), tipificados em seis áreas homogêneas espacialmente distintas: Matopiba, Norte de Minas, Vetor Centro-oeste, Semiárido, Norte Águas e Norte Estradas 27.

No presente artigo são analisados resultados do oeste do Pará (regiões de saúde do Baixo Amazonas e Tapajós) com amostra de cinco municípios rurais remotos: três Norte Águas, marcados pela dinâmica dos rios; e dois Norte Estradas, caracterizados por desenvolvimento recente a partir da expansão rodoviária.

O trabalho de campo ocorreu entre maio e agosto de 2019. O ponto de partida foi o Município de Santarém com trajetos para os municípios rurais remotos por embarcação (entre 4 horas de lancha e 14 horas de barco de linha) ou caminhonete institucional (4 a 15 horas). A entrada no campo em cada município e unidades básicas de saúde (UBS), em geral de difícil acesso, foi apoiada pelas Secretarias Municipais de Saúde (SMS). Realizou-se entrevistas com ACS e enfermeiros (ENF) dos cinco municípios, em uma UBS na sede e uma no interior, totalizando 23 entrevistas (12 ACS e 11 enfermeiras), tendo como critério de seleção os profissionais com maior tempo de atuação nas equipes.

O roteiro das entrevistas incluiu características do território, acesso e processo de trabalho, e o cuidado referente a três traçadores: câncer de colo de útero, hipertensão arterial e pré-natal, parto e puerpério. As entrevistas duraram de uma hora e meia a três horas, foram transcritas e realizada análise de conteúdo temática 28 . A categorização temática envolveu eixos emergentes da análise sistemática e contrastante das percepções e experiências dos participantes da pesquisa, resultando em duas ênfases do processo de trabalho dos ACS: escopo de práticas e qualificação (Quadro 1).

O projeto da pesquisa nacional foi aprovado pelo Comitê de Ética e Pesquisa da Escola Nacional de Saúde Pública Sergio Arouca, Fundação Oswaldo Cruz (CEP/ENSP/Fiocruz, CAAE 92280918.3.0000.5240 e parecer no 2.832.559), com entrevista autorizada pelos participantes e preservação de anonimato nas análises.

Dos 12 entrevistados, cinco ACS atuavam na sede e sete no interior, sendo a maioria de ESF (10), com 11 anos ou mais de atuação e concursados. Das 11 enfermeiras, oito tinham até dois anos de atuação na APS do município e a maioria contratos temporários (Tabela 1). Como formação específica para ACS, somente um município referiu curso introdutório (1ENF2), ocorrido após processo seletivo.

\section{Resultados}

\section{Contexto da pesquisa}

Os municípios rurais remotos estudados têm população entre 12 mil e 40 mil habitantes, baixo produto interno bruto (PIB) per capita e baixa arrecadação tributária, salvo um que recebia royalties de usina hidrelétrica (Tabela 2). As populações tinham baixa renda, com número expressivo de famílias beneficiárias do Programa Bolsa Família e escassas fontes de renda (prefeitura, comércio, pesca artesanal, produção de farinha ou agricultura familiar de subsistência).

As condições de saneamento básico são precárias em todos os municípios, com situação agravada no interior. Na sede, o abastecimento de água é feito por microssistemas com distribuição por poços artesianos e caixas d'água para o armazenamento sem tratamento, sendo frequente no interior, o consumo de água do rio. Uma iniciativa diferenciada foi o Sistema Salta Z (solução alternativa coletiva simplificada de tratamento de água para consumo humano), instalado em um dos municípios pela Fundação Nacional de Saúde (Funasa). Inexistia esgotamento sanitário e era precária a coleta de lixo.

Os municípios tinham forte presença de população rural (53\% a 80\%), com baixa densidade demográfica, povoação muito esparsa e grande número de pequenas comunidades/vilas no território. As populações tradicionais mais comuns eram ribeirinhas - pescadores artesanais ou extrativistas - e indígenas, presentes principalmente no interior. As populações ribeirinhas vivem às margens de rios 
Quadro 1

Matriz para análise da atuação dos agentes comunitários de saúde (ACS) em municípios rurais remotos. Oeste do Pará, Brasil, 2019.

\begin{tabular}{|c|c|c|}
\hline DIMENSÕES DE ANÁLISE & COMPONENTES & CATEGORIAS \\
\hline \multirow{12}{*}{$\begin{array}{l}\text { Processo de trabalho dos } \\
\text { ACS (escopo de práticas) }\end{array}$} & \multirow[t]{2}{*}{ Acompanhamento familiar } & Identificação de problemas de saúde \\
\hline & & Identificação de famílias e casos de maior vulnerabilidade social \\
\hline & \multirow{3}{*}{$\begin{array}{l}\text { Cuidados e medidas } \\
\text { preventivas individuais }\end{array}$} & Procedimentos individuais \\
\hline & & Vacinação \\
\hline & & $\begin{array}{c}\text { Acompanhamento de pessoas com hipertensão arterial; gestantes (pré-natal, parto } \\
\text { e puerpério); e mulheres na prevenção de câncer de colo de útero }\end{array}$ \\
\hline & \multirow{4}{*}{$\begin{array}{l}\text { Abordagem coletiva/ } \\
\text { comunitária }\end{array}$} & Territorialização \\
\hline & & Ações comunitárias e intersetoriais - Programa Bolsa Família e PSE \\
\hline & & Distribuição de hipoclorito \\
\hline & & Educação em saúde \\
\hline & \multirow[t]{2}{*}{ Tarefas administrativas } & Cadastro e produção preenchidos no e-SUS APS \\
\hline & & Orientações sobre funcionamento da UBS e atenção especializada \\
\hline & Visitas domiciliares & Dimensões das visitas domiciliares \\
\hline \multirow{4}{*}{$\begin{array}{l}\text { Processo de trabalho dos } \\
\text { ACS (qualificação) }\end{array}$} & \multirow{4}{*}{$\begin{array}{l}\text { Qualificação do ACS para o } \\
\text { trabalho }\end{array}$} & Educação permanente \\
\hline & & Acompanhamento do trabalho do ACS \\
\hline & & Apoio da gestão municipal (materiais e transporte) \\
\hline & & Motivação dos ACS \\
\hline
\end{tabular}

APS: atenção primária à saúde; e-SUS APS: e-SUS Atenção Primária; PSE: Programa Saúde na Escola; UBS: unidades básicas de saúde.

Fonte: elaboração própria.

na Amazônia brasileira, com seus modos de vida consonantes com a dinâmica das águas (cheias e vazantes) e acesso exclusivo fluvial.

A atenção à saúde nos municípios rurais remotos estudados era prestada exclusivamente pelo SUS, em UBS, postos de saúde, unidades mistas ou pequenos hospitais (presentes nos cinco casos). Todos os municípios implementaram equipes ESF, com cobertura entre 56\% e 100\%. Em quatro municípios havia equipes de Estratégia de Agentes Comunitários de Saúde (EACS) em territórios rurais. Em geral, havia apenas uma equipe por UBS. As UBS da sede contavam com equipes ESF, o que nem sempre era possível no interior

\section{Processo de trabalho dos ACS (escopo de práticas)}

Os ACS atuavam na sede ou em pequenas comunidades do interior, conforme o seu local de domicílio. O cadastramento das famílias, em geral, estava em atualização no Sistema de Informação em Saúde para a Atenção Básica (SISAB/e-SUS APS). As microáreas eram definidas pela SMS, conforme distância e distribuição das comunidades no território, com grande variação do número de famílias/ pessoas adscritas por ACS. No interior dos municípios, os ACS residiam na comunidade com o maior aglomerado populacional, embora fossem responsáveis pela cobertura de várias pequenas comunidades do entorno.

O número de ACS por equipe atenção básica variou de 2 a 22 agentes, conforme o tipo de equipe, ESF ou EACS. Havia mais ACS no interior do que nas sedes municipais, com baixo número de famílias acompanhadas nas áreas mais esparsas. Em um município, ACS de ramais de difícil acesso acompanhavam um mínimo de 20 famílias/200 pessoas em 130 ramais de responsabilidade da equipe (1ENF2). ACS da sede dos municípios acompanhavam cerca de 700 pessoas (3ACS1/1ACS1).

Os agentes atuavam em equipes ESF com médico, enfermeiro, técnico de enfermagem, dois ou mais ACS, responsáveis por 3.000 até 8.000 pessoas (3ENF2/4ENF1). Em quatro municípios, havia 
Tabela 1

Perfil dos entrevistados (agentes comunitários de saúde - ACS e enfermeiros) em municípios rurais remotos. Oeste do Pará, Brasil, 2019.

\begin{tabular}{|c|c|c|}
\hline & $\operatorname{ACS}(n=12)$ & Enfermeiros $(n=11)$ \\
\hline \multicolumn{3}{|l|}{ Tipo de território } \\
\hline Norte Águas & 7 & 6 \\
\hline Norte Estradas & 5 & 5 \\
\hline \multicolumn{3}{|l|}{ Tipo de equipes } \\
\hline ESF & 10 & 9 \\
\hline ACS & 2 & 2 \\
\hline \multicolumn{3}{|l|}{ Localização da UBS } \\
\hline Sede & 5 & 5 \\
\hline Interior & 7 & 6 \\
\hline \multicolumn{3}{|l|}{ Sexo } \\
\hline Feminino & 9 & 11 \\
\hline Masculino & 3 & 0 \\
\hline \multicolumn{3}{|l|}{ Idade (anos) } \\
\hline $19-28$ & 0 & 4 \\
\hline 29-39 & 8 & 4 \\
\hline $40-50$ & 3 & 2 \\
\hline 51 ou mais & 1 & 1 \\
\hline \multicolumn{3}{|l|}{ Tempo de atuação em APS (anos) } \\
\hline Até 2 & 0 & 8 \\
\hline $3-6$ & 4 & 1 \\
\hline $7-10$ & 0 & 0 \\
\hline 11 ou mais & 8 & 2 \\
\hline \multicolumn{3}{|l|}{ Escolaridade } \\
\hline Ensino Fundamental completo & 1 & - \\
\hline Ensino Médio completo & 6 & - \\
\hline Ensino Médio completo (técnico Enfermagem) & 3 & - \\
\hline Ensino Superior & 2 & 5 \\
\hline Pós-graduação na saúde & 0 & 6 \\
\hline \multicolumn{3}{|l|}{ Participação em órgão colegiado } \\
\hline Sim (sindicato dos trabalhadores da saúde pública) & 8 & 0 \\
\hline Não & 4 & 11 \\
\hline \multicolumn{3}{|l|}{ Vínculo servidor público municipal } \\
\hline Sim & 12 & 3 \\
\hline Não (contrato temporário) & 0 & 8 \\
\hline
\end{tabular}

APS: atenção primária à saúde; ESF: Estratégia Saúde da Família; UBS: unidades básicas de saúde.

Fonte: elaboração própria.

ACS de equipes EACS em áreas rurais, supervisionados por um enfermeiro. Em dois municípios, existiam postos de saúde no interior, com equipe de um ACS, um técnico de enfermagem e um microscopista. A totalidade de médicos da APS dos municípios estudados integrava o Programa Mais Médicos.

O escopo de práticas dos ACS nos municípios rurais remotos foi sistematizado em: acompanhamento familiar, cuidados e medidas preventivas individuais, abordagem coletiva/comunitária e atividades administrativas, sendo as visitas domiciliares a sua principal atividade. 
Tabela 2

Indicadores demográficos, socioeconômicos e de atenção básica dos municípios rurais remotos selecionados. Oeste do Pará, Brasil, 2019.

\begin{tabular}{|c|c|c|c|c|c|}
\hline & $\begin{array}{l}\text { Município rural } \\
\text { remoto } 1\end{array}$ & $\begin{array}{l}\text { Município rural } \\
\text { remoto } 2\end{array}$ & $\begin{array}{l}\text { Município rural } \\
\text { remoto } 3\end{array}$ & $\begin{array}{l}\text { Município rural } \\
\text { remoto } 4\end{array}$ & $\begin{array}{l}\text { Município rural } \\
\text { remoto } 5\end{array}$ \\
\hline Região de saúde (2014) & Tapajós & Tapajós & Tapajós & Baixo Amazonas & Baixo Amazonas \\
\hline Tipo de território * & Norte estradas & Norte estradas & Norte águas & Norte águas & Norte águas \\
\hline \multicolumn{6}{|l|}{ Indicadores demográficos ** (2010) } \\
\hline População total n & 40.087 & 14.103 & 15.849 & 12.254 & 29.349 \\
\hline População urbana n (\%) & $15.273(38,1)$ & $4.930(35,0)$ & $3.179(20,1)$ & $5.781(47,2)$ & $8.959(30,5)$ \\
\hline População rural n (\%) & $24.814(61,9)$ & $9.173(65,0)$ & $12.670(79,9)$ & $6.473(52,8)$ & $20.390(69,5)$ \\
\hline Área territorial $\left(\mathrm{km}^{2}\right)$ & 7.054 & 53.539 & 17.155 & 1.437 & 12.655 \\
\hline Densidade demográfica (habitantes/km²) & 5,68 & 0,26 & 0,92 & 8,53 & 2,31 \\
\hline \multicolumn{6}{|l|}{ Indicadores socioeconômicos } \\
\hline 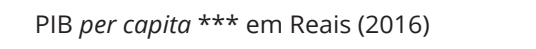 & 7.119 & 26.873 & 7.685 & 7.880 & 9.606 \\
\hline IDHM ** (2010) & 0,548 & 0,505 & 0,541 & 0,578 & 0,523 \\
\hline $\begin{array}{l}\text { \% população em domicílios com banheiro } \\
\text { e água encanada ** (2010) }\end{array}$ & 27,7 & 20,5 & 24,1 & 19,1 & 16,0 \\
\hline $\begin{array}{l}\text { \% população beneficiária do Programa } \\
\text { Bolsa Família \#,\#\# (2014) }\end{array}$ & 32,9 & 24,6 & 65,8 & 68,8 & 84,7 \\
\hline \multicolumn{6}{|l|}{$\begin{array}{l}\text { Indicadores de atenção básica } \\
\text { (agosto/2019) }\end{array}$} \\
\hline Número total de UBS \#\#\# & 9 & 11 & 7 & 8 & 12 \\
\hline Número de UBS sede \#\#\# & 5 & 2 & 1 & 3 & 1 \\
\hline Número de UBS rural \#\#\# & 4 & 9 & 6 & 5 & 11 \\
\hline$\%$ cobertura de ESF $\S$ & 48,8 & 77,5 & 100,0 & 100,0 & 69,3 \\
\hline Número de equipes de ESF §§ & 6 & 2 & 6 & 4 & 6 \\
\hline Número de equipes de NASF $₫ \S$ & 1 & 0 & 0 & 1 & 0 \\
\hline Número de equipes de EACS §§ & 7 & 1 & 0 & 1 & 3 \\
\hline $\begin{array}{l}\text { Número de ACS (equipes de EACS + } \\
\text { equipes de ESF) } \S \S\end{array}$ & $125(66+59)$ & $21(11+10)$ & $54(0+54)$ & $27(9+18)$ & $85(34+51)$ \\
\hline
\end{tabular}

ACS: agentes comunitários de saúde; EACS: Estratégia de Agentes Comunitários de Saúde; ESF: Estratégia Saúde da Família; IDHM: Índice de Desenvolvimento Humano Municipal; NASF: Núcleo Ampliado de Saúde da Família; PIB: Produto Interno Bruto; UBS: unidade básica de saúde.

* Fausto et al. 27;

** Atlas do Desenvolvimento Humano no Brasil, 2010. (http://www.atlasbrasil.org.br/2013/pt/consulta/, acessado em 21/Out/2019);

*** Instituto Brasileiro de Geografia e Estatística (https://cidades.ibge.gov.br/brasil/panorama, acessado em 21/Out/2019);

\# Banco de indicadores da Pesquisa Regiões e Redes, 2014 (http://www.resbr.net.br/indicadores/view/indicadores.php?clrSession=true, acessado em 21/Out/2019);

\#\# Cadastro Nacional de Estabelecimentos de Saúde (CNES). Consultas de estabelecimentos (http://cnes.datasus.gov.br/pages/estabelecimentos/ consulta.jsp, acessado em 21/Out/2019) e verificação durante a visita. Nas UBS rurais estão contabilizados os postos de saúde e UBS, com exceção dos postos de saúde indígenas;

\#\#\# Quantidade de beneficiários do Programa Bolsa Família, em 2014/População total em 2014*100;

§ Portal do gestor da Atenção Básica, 2019 (https://egestorab.saude.gov.br/paginas/acessoPublico/relatorios/relHistoricoCoberturaAB.xhtml, acessado em 21/Out/2019);

$\S \S$ CNES, agosto/2019. Item consultas de equipes (http://cnes2.datasus.gov.br/Lista_Tot_Equipes.asp, acessado em 21/Out/2019). 


\section{Acompanhamento familiar}

O acompanhamento familiar é realizado por meio de visita domiciliar. São realizadas pelos ACS da sede e do interior, rotineiramente (7-8 visitas por dia), em geral a cada um ou dois meses, com periodicidade condicionada pelo vínculo com as famílias, as necessidades e as condições de acesso ao domicílio.

No acompanhamento familiar destaca-se o papel do ACS na identificação de problemas de saúde e identificação de famílias e casos de maior vulnerabilidade. Por conhecerem o cotidiano das famílias, contribuem para a identificação dos episódios de violência doméstica, alcoolismo, desnutrição, idosos que moram sozinhos, por vezes acionando os serviços de assistência social (5ENF1/5ENF2/1ENF2).

Os ACS atuavam como "ponte" de acesso das famílias aos serviços, identificando a necessidade de visita domiciliar dos demais membros da equipe, suspeita de enfermidade que demandasse assistência médica e mediando o acesso a transporte sanitário em casos mais urgentes (Quadro 2).

\section{Cuidados e medidas preventivas individuais}

Durante as visitas, os ACS acompanham os usuários de programas prioritários de saúde pública com ações preventivas e de educação em saúde. Monitoram a atualização da caderneta de vacinação infantil, a realização de pré-natal por gestantes e orientam os portadores de hipertensão (1ENF2/2ENF1/ 3ENF2). As orientações envolvem temas como alimentação saudável, atividade física, higiene, vacinação, amamentação e uso adequado de medicamentos (1ACS2/2ACS1).

A busca ativa, embora realizada sem frequência regular, era acompanhada de orientações sobre: consultas ou exames atrasados para gestantes; importância, frequência, dias de coleta e busca de resultados de preventivo (1ENF1/1ENF2/2ENF1/3ENF1/4ENF2/5ENF2); e apoio aos usuários com hipertensão arterial no acesso a medicamentos (2ENF2/4ENF2/2ENF1/1ENF1).

Além do acompanhamento aos grupos prioritários, os ACS do interior do município realizavam ações no domicílio, incomuns na prática dos agentes da sede, entre as quais:

(1) Aferição de pressão arterial: a maior parte dos ACS aferia a pressão de usuários e se responsabilizava pelo MAPA (monitorização ambulatorial da pressão arterial) por solicitação do médico da equipe. O esfigmomanômetro era disponibilizado pela Secretaria Municipal de Saúde (SMS) ou adquirido pelo ACS (4ENF1/1ENF2/1ENF1/3ACS2);

(2) Entrega domiciliar de medicamentos de uso contínuo, principalmente para hipertensão arterial, para usuários de áreas mais distantes (2ENF1/2ENF2/3ENF2/4ENF1/4ENF2/5ENF2);

(3) Agendamento de consultas e exames na UBS a partir da visita domiciliar (1ENF1/1ENF2/5ACS1);

(4) Prevenção de malária: orientações em regiões endêmicas para o uso de mosquiteiros impregnados, atuação com equipe de vigilância nos surtos e eliminação de focos. Alguns ACS realizavam coleta de sangue para exame de gota espessa para malária (2ACS2/5ACS2);

(5) Curativos simples (1ACS2/5ACS2);

(6) Transporte realizado pelo próprio agente (moto própria ou rabeta) no deslocamento para urgências e partos (2ACS2);

(7) Distribuição e orientação sobre hipoclorito, muitas vezes como a única forma de cuidado com a água disponibilizada à população (1ENF2/1ACS2/3ACS1/4ACS1).

Entre as ações preventivas, destaca-se ainda a participação de ACS na ação de bloqueio vacinal de surto recente de sarampo em dois municípios.

\section{Abordagem coletiva/comunitária}

O trabalho dos ACS era territorializado pela adscrição de famílias sob a sua responsabilidade. Em três municípios, foram responsáveis pelo desenho do mapa do território (3ENF2/3ENF1/2ACS1/ 1ACS3), auxiliando a equipe no acompanhamento das famílias.

A ação dos ACS é central em iniciativas de articulação com programas de outros setores como o Programa Bolsa Família e o Programa Saúde na Escola (PSE). Os Agentes desempenhavam um papel decisivo no acompanhamento das condicionalidades do Programa Bolsa Família nos domicílios, em mutirões nas UBS ou em equipamentos sociais da comunidade. Em geral, os ACS do interior faziam o 
Quadro 2

Processo de trabalho dos ACS (agentes comunitários de saúde - escopo de práticas), municípios rurais remotos. Oeste do Pará, Brasil, 2019.

\begin{tabular}{|c|c|}
\hline TIPOS DE AÇÕES & RELATOS DOS ENTREVISTADOS \\
\hline $\begin{array}{l}\text { Acompar } \\
\text { familiar }\end{array}$ & $\begin{array}{l}\text { Identificação de problemas de saúde: "Uma comunidade que é bem distante, cerca de } 30 \text { km, teve dois casos de leishmaniose, } \\
\text { então ele viu aquela situação na visita domiciliar, o paciente não relatou nada, ele só observou aquela ferida que não cicatrizava } \\
\text { e já encaminhou. E aí ele já falou, enfermeira estou encaminhando o paciente assim e realmente deu positivo" (3ENF2). } \\
\text { Identificação de famílias e casos de maior vulnerabilidade social: "Eles [ACS] que trazem todos os casos para mim. Às vezes } \\
\text { tem uma família que está com uma criança, em que a mãe e o pai eram alcoólatras e a criança especial, e não estavam cuidando } \\
\text { dessa criança, a criança já estava com pneumonia e não estavam cuidando. Então a ACS já trouxe o caso para mim e a gente } \\
\text { conseguiu levar essa criança até o hospital, essa criança já estava desnutrida (...). Hoje em dia se você ver ela está uma criança } \\
\text { totalmente diferente, tá gordinha, bonitinha, conseguimos aposentar [o pai] através da assistente social. São casos que a gente } \\
\text { vai resolvendo através do ACS pois não temos muita facilidade para estar saindo da unidade devido à demanda ser muito } \\
\text { grande. O ACS já me traz o caso e a gente dá um jeito de resolver na medida do possível" (1ENF2). }\end{array}$ \\
\hline $\begin{array}{l}\text { Cuidados e } \\
\text { preventivas } \\
\text { individuais }\end{array}$ & 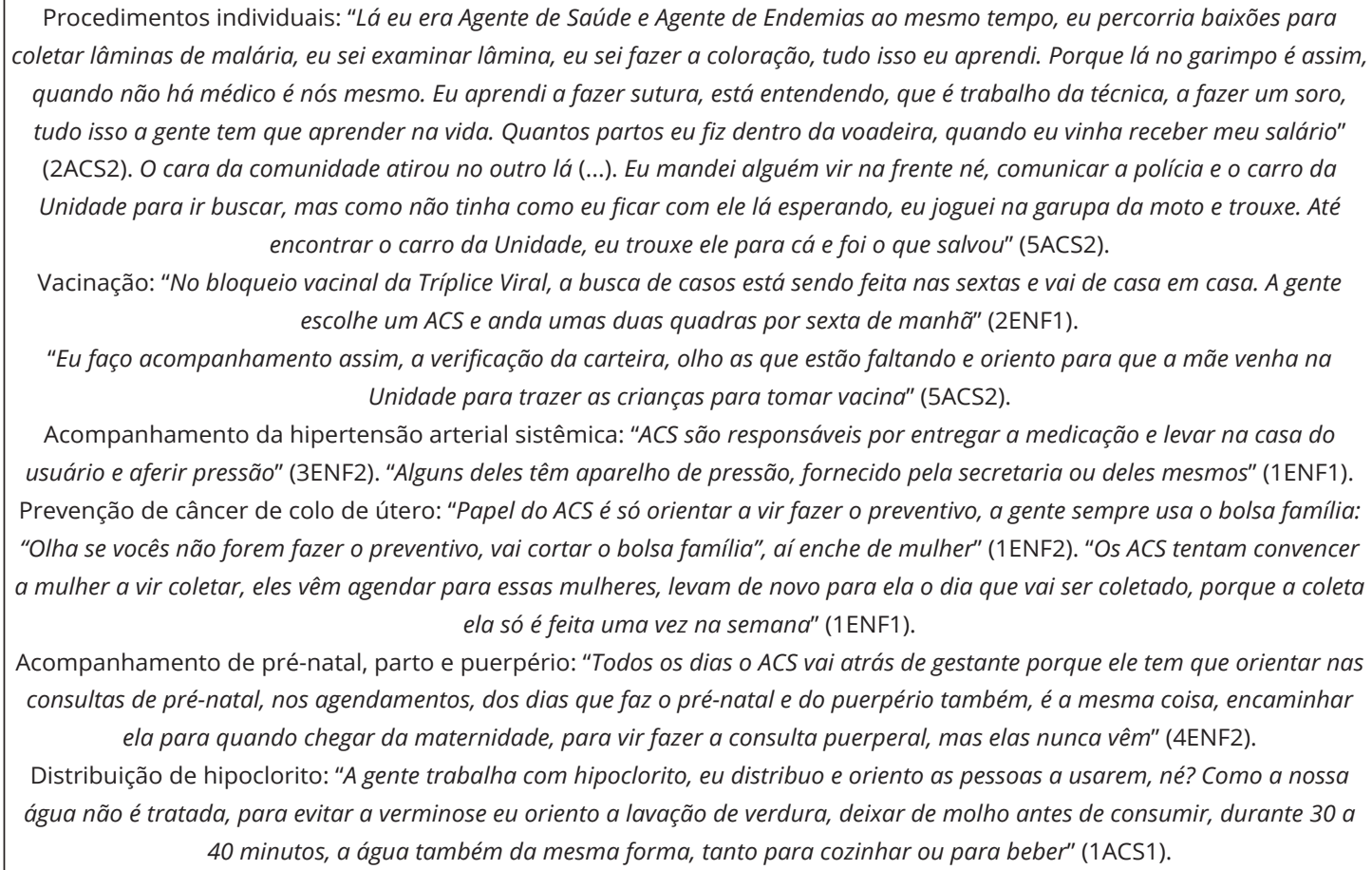 \\
\hline $\begin{array}{l}\text { Abordagem } \\
\text { coletiva/ } \\
\text { comunitária }\end{array}$ & 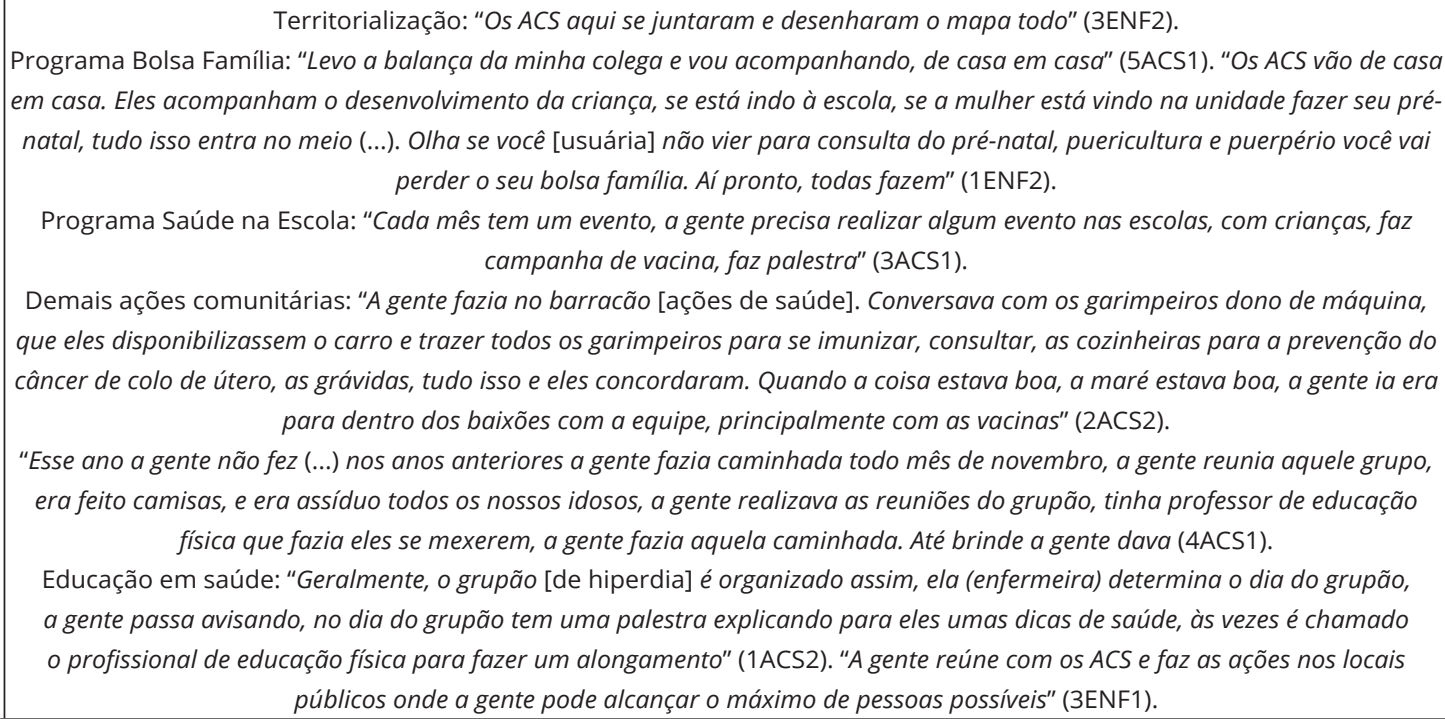 \\
\hline
\end{tabular}

(continua) 
Quadro 2 (continuação)

\begin{tabular}{|c|c|}
\hline TIPOS DE AÇÕES & RELATOS DOS ENTREVISTADOS \\
\hline $\begin{array}{l}\text { Tarefas } \\
\text { administrativas }\end{array}$ & $\begin{array}{l}\text { Cadastro e produção preenchidos no e-SUS APS: "Aqui eu tenho meus cadernos, das grávidas, tenho do hiperdia, da diabetes, } \\
\text { tudinho. (...) porque quando eu for fazer a produção eu já tenho tudo aqui, tudo já mastigadinho para entregar para enfermeira" } \\
\text { (2ACS2). } \\
\text { "As atualizações do cadastro da família é diariamente que eu faço, todo dia no tablet (...). Com o tablet melhorou demais, } \\
\text { 100\%. Antes eu digitava a produção, mandava para Secretaria e às vezes demorava vários dias para ser digitado e aqui não, } \\
\text { tu conectou já vai on-line. Se não tiver internet, fica registrado tudo lá e quando conectar, envia. Então, eu acho que foi uma } \\
\text { evolução muito positiva" (1ACS1). } \\
\text { "Orientações sobre funcionamento da UBS: Oriento eles [usuários] que 7h a doutora atende a quantidade de fichas que ela tem } \\
\text { para atender e volta a atender novamente às 13h, e atende até terminar as fichas" (1ACS3). }\end{array}$ \\
\hline Visit & 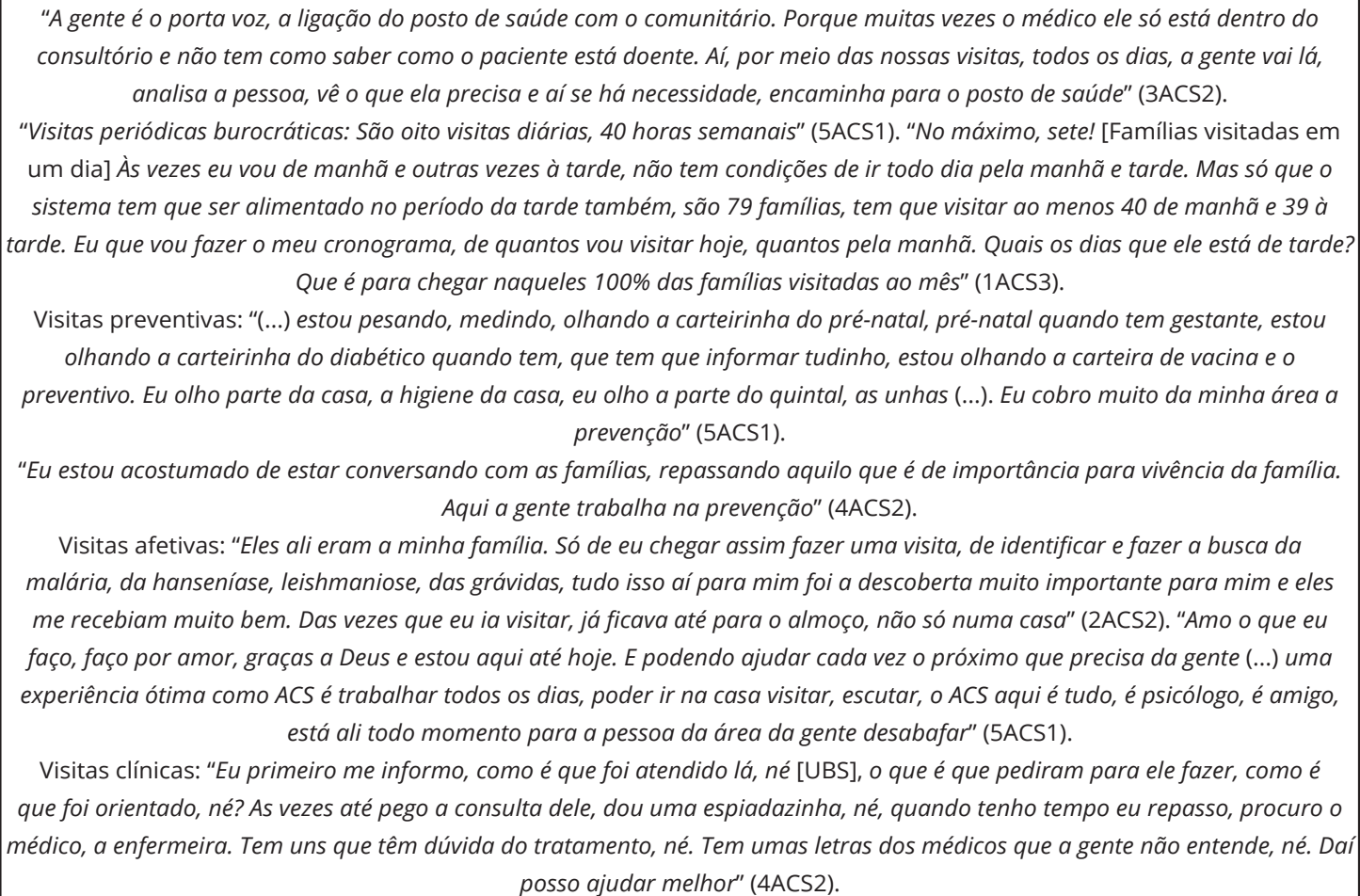 \\
\hline
\end{tabular}

ENF: enfermeiro; UBS: unidades básicas de saúde.

Fonte: entrevistas da pesquisa.

acompanhamento no domicílio e os ACS da sede, na UBS (5ENF1/3ENF2/1ENF2/5ENF2). Realizavam o acompanhamento da carteira vacinal, do crescimento e desenvolvimento infantil, atualização do pré-natal e frequência escolar (5ENF1/5ENF2/1ENF2), considerando que o Programa Bolsa Família era a principal garantia das crianças na escola e do cartão vacinal atualizado. Adicionalmente, incluíam acompanhamento de preventivo como condicionalidade Programa Bolsa Família (5ENF1/1ENF2/5ACS1/1ACS2). Identificou-se um certo exercício de controle autoritário dos ACS quanto ao preventivo e pré-natal, incentivado pela enfermagem, com ameaças às mulheres de perda do Programa Bolsa Família caso não os realizassem. No caso do PSE, os agentes acompanhavam as equipes no desenvolvimento das ações nas escolas, principalmente a prevenção da cárie dentária e a antropometria.

As ações comunitárias eram escassas com ausência ou insuficiência de ações coletivas de educação em saúde, que ocorriam no formato dos "grupões" promovidos pela equipe de saúde com orientações gerais sobre hábitos, muitas vezes associadas à distribuição de medicamentos, com a participação pontual dos ACS na mobilização prévia e no dia da ação (3ENF1/4ENF1/2ENF1). Os "grupões" costumavam ter caráter de confraternização e criação de vínculo serviço/população, com lanches financiados coletivamente pelos profissionais de saúde. Em caso de desabastecimento de medicamentos, 
os ACS apontaram redução na participação nos grupos. Nas comunidades, quando ocorriam, eram no formato de mutirão para procedimentos.

\section{Atividades administrativas}

Atividades de caráter administrativo compõem o cotidiano dos ACS, principalmente, o registro da produção no SISAB/e-SUS APS e orientações sobre o funcionamento da UBS e a atenção especializada.

Os ACS são os responsáveis pelo preenchimento no e-SUS APS de cadastros individual e domiciliar, visita e ações coletivas. Agentes de três municípios utilizavam tablet para o registro da produção, e outros dois usavam fichas de papel (coleta de dados simplificada). Nos municípios em que os ACS possuíam tablets, registravam a visita domiciliar e enviavam para a SMS assim que acessavam a internet (2ENF1/2ENF2/1ENF2/1ENF1).

Os profissionais relataram aprimoramento no registro dos ACS com a utilização dos tablets, facilitando as atualizações cadastrais. Ainda assim, havia a preocupação dos ACS em manter registros em papel, por segurança e para a comprovação do trabalho na supervisão da enfermagem.

Uma atividade comum dos ACS, valorizada pelos enfermeiros, foi orientar os usuários sobre o funcionamento da UBS (4ENF1/1ENF2/2ENF1), informando fluxos de atendimento, ações e serviços ofertados, escala de atendimento dos profissionais e dinâmicas de trabalho da equipe. Comumente, os ACS também avisavam sobre o agendamento da consulta especializada no domicílio do usuário (a pedido da SMS ou da enfermeira) (4ENF1/3ENF1/2ENF10/3ENF2/5ENF1). Em dois municípios, as enfermeiras mandavam um "bilhetinho" pelo transporte escolar para o ACS da região (5ENF2/2ENF1). Ademais, os Agentes informavam às equipes se o usuário fez a consulta ou voltou para casa na pós-internação (3ENF1/3ENF2).

\section{Visitas domiciliares}

O trabalho dos ACS é centrado na realização das visita domiciliar às famílias adscritas. Regularmente realizadas por todos os ACS, as visitas domiciliares adquirem conotações e componentes distintos, concomitantes e complementares, a depender do foco e objetivos, seja de cadastro, cuidado ou informação, podendo ser categorizadas em:

(a) Visitas periódicas burocráticas - não há agravos ou doenças na família, sendo visitas mais genéricas e rápidas para possíveis dúvidas, convocações e atualização de cadastro. Têm como foco a produtividade do ACS que deve contabilizar um número mínimo de visitas por semana, ou informes da enfermeira. Não são percebidas novas necessidades ou questões de determinação social do processo saúde/doença (5ACS1/1ACS3);

(b) Visitas preventivas - têm como foco as orientações sobre saúde para os grupos prioritários e ações de saúde pública. Envolvem o cuidado na perspectiva da família, cuidados no domicílio e no território (5ACS1/4CS2/3ACS1);

(c) Visitas afetivas - visita como meio de convívio social, fortalecimento de vínculo. Em geral são mais demoradas. Intensificam a identidade do ACS como laço entre a comunidade e o serviço, reforçam o sentido de pertencimento dos agentes no território e sua relação com as famílias. Por seu caráter ampliado, permitem melhor abordagem das necessidades sociais (2ACS2/5ACS1);

(d) Visitas clínicas - voltadas aos procedimentos individuais realizados pelos ACS no domicílio para pessoas com algum agravo específico que necessite de continuidade no acompanhamento ou que tenham dificuldade de deslocamento (4ACS2).

\section{Qualificação do processo de trabalho dos ACS}

No processo de trabalho dos ACS foi identificado um conjunto de ações capazes de potencializar ou limitar o desenvolvimento do seu escopo ampliado de práticas: educação permanente, acompanhamento do trabalho, apoio da gestão e motivação.

O estudo tratou de um aspecto da qualificação, relacionado à educação permanente, embora se reconheça que a formação profissional também tem implicações importantes para a delimita- 
ção do escopo de práticas, com efeitos para o processo de trabalho e a valorização profissional dos trabalhadores.

\section{Educação permanente}

Em geral, observou-se insuficiência de educação permanente ofertada sistematicamente para os ACS. As SMS concentram alguma formação no momento da entrega da produção (uma vez/mês), que coincide com a busca do salário na sede (para ACS do interior). Contudo, a maior parte dos entrevistados apontou que nem mesmo nesses momentos ocorria algum tipo de capacitação. Em dois municípios, os ACS passaram por treinamento na implantação do e-SUS APS (1ACS3/5ENF1), para aprender a aferir pressão arterial (3ENF2/1ACS3) e um deles destacou a importância do Núcleo Ampliado de Saúde da Família (NASF) na sua atuação (1ACS3/1ENF1). Uma das consequências da insuficiência de capacitação eram as orientações de saúde dos ACS pautadas por experiências pessoais.

\section{Acompanhamento do trabalho do ACS}

As enfermeiras das equipes ou a coordenação da atenção básica eram as responsáveis pela supervisão, que ocorria de forma variada entre os municípios e com baixa frequência. Em geral, os ACS da sede possuíam um diálogo mais frequente com as enfermeiras e os ACS do interior, muitos de antigas equipes PACS, tinham maior relação com a coordenação atenção básica.

A supervisão dos ACS e a reunião de equipe foram mencionadas nas entrevistas com o mesmo sentido. Geralmente, a supervisão é realizada em reuniões da equipe, pouco frequentes, sem a participação de todos os membros e, muitas vezes, reduzidas à verificação de produção dos Agentes (3ENF1/2ENF1/1ENF1/1ENF2). Uma das enfermeiras realizava a supervisão diretamente com a população, verificando o "desempenho" dos ACS por questionários, condução aparentemente de lógica punitiva (5ENF1). Um dos ACS citou que nessas reuniões a enfermeira realiza o controle da produção de visita domiciliar por assinatura em ficha específica (1ACS3).

Outros temas nas reuniões de equipe foram a organização de atividades de educação em saúde, a mobilização para campanhas de vacinação, a organização de atendimentos na UBS, ou o tema específico de alguma comunidade.

A frequente carência de profissionais, com elevada rotatividade de médicos e enfermeiros, dificultava o trabalho dos ACS e sua educação permanente. Na área rural, os ACS pouco participavam do cotidiano das equipes, cujo contato limitava-se a escassas visitas domiciliares acompanhando outros profissionais.

\section{Apoio da gestão municipal (insumos e transporte)}

O apoio material para o trabalho dos ACS variou entre os municípios. Equipamentos de proteção individual (EPI) e materiais para o trabalho dos ACS no território eram disponibilizados em parte ou em seu conjunto pelos gestores. Dentre os EPI foram citados bota, boné, protetor solar, uniforme. Os materiais incluíram bolsa/mochila, balança, esfigmomanômetro, soro de reidratação oral, hipoclorito e tablet. Contudo, muitas vezes, faltava a reposição de ambos (5ACS2/3ACS1/2ACS2). Em geral, os ACS de áreas rurais possuíam balança e esfigmomanômetro.

Os ACS sinalizaram a necessidade de apoio municipal para maior disponibilidade de transporte para visita domiciliar e para pacientes. Para o seu trabalho utilizam diversificados tipos de transporte: cavalo, bicicleta, moto e pequenas embarcações (bajara/rabeta/canoa).

Em quatro municípios, observou-se o fornecimento de bicicletas, canoas, motos institucionais e/ ou cota mensal de combustível para os ACS (1ENF2/2ACS2/5ACS2/4ACS2), contudo, em três havia descontinuidade no fornecimento (2ACS2/4ACS2/5ACS2). Apesar de dificuldades com transporte, os ACS não deixavam de informar e mobilizar a população, muitas vezes com recursos próprios. 


\section{Motivação dos ACS}

Os ACS mostraram-se muito motivados para desempenhar o seu trabalho, especialmente os do interior. Geralmente, haviam ingressado sem conhecimento sobre a função, mas durante a atuação percebiam a sua importância: "A comunidade ensina como podemos ajudar" (5ACS3). "Trazer a realidade da família até a equipe" (1ACS3), é como outro ACS define uma das suas funções mais importantes (Quadro 3).

\section{Quadro 3}

Qualificação para o processo de trabalho do agentes comunitários de saúde (ACS), municípios rurais remotos. Oeste do Pará, Brasil, 2019.

\begin{tabular}{|c|c|}
\hline TIPOS DE AÇÕES & RELATOS DOS ENTREVISTADOS \\
\hline Educação permanente & $\begin{array}{c}\text { "Difícil a gente ter treinamento, e a gente precisa, vou dizer que eu pesquiso muita coisa na internet quando tenho dúvida" } \\
\text { (2ACS1). "Os agentes receberam treinamento quando chegaram, todos eles passaram um período de dois meses de } \\
\text { treinamento" (1ENF2). }\end{array}$ \\
\hline $\begin{array}{l}\text { Acompanhamento do } \\
\text { trabalho dos ACS }\end{array}$ & $\begin{array}{l}\text { "A equipe que se reúne é só dos ACS com a equipe de enfermagem, médico de vez em quando, mas é raro fazer uma } \\
\text { reunião com toda a equipe, porque geralmente nem todos estão presentes na reunião, mas não é tão frequente não essa } \\
\text { reunião. É uma vez por mês com os ACS" (3ENF1). } \\
\text { "Na reunião de equipe participa a enfermeira responsável pelo posto, que recebe a produção e aí tem aquelas fichas das } \\
\text { familias que visitamos e a família assina, ela vai olhar tudo para poder assinar e devolver para gente (...). Sempre nessas } \\
\text { reuniões, é só para assinar mesmo que fizemos as visitas e fazer as orientações que a enfermeira acha cabível" (1ACS3). }\end{array}$ \\
\hline $\begin{array}{l}\text { Apoio da gestão } \\
\text { municipal (insumos e } \\
\text { transporte) }\end{array}$ & 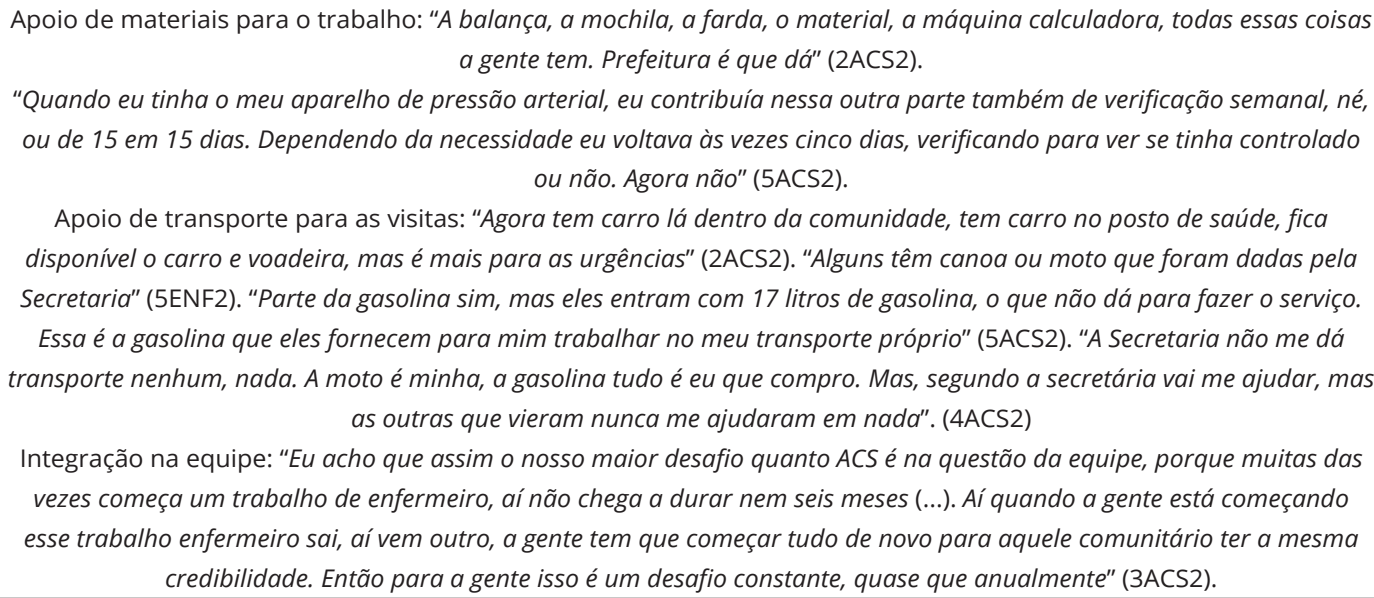 \\
\hline Motivação dos ACS & $\begin{array}{l}\text { "Eu acho que isso aí já vem da vocação da gente (...). Eu tinha esse sonho [de trabalhar na saúde] e graças a Deus até hoje } \\
\text { eu lembro disso e gosto sim do meu trabalho, mesmo todo dia de pé, corria para voltar. Eu estou acostumada de estar } \\
\text { conversando com as famílias, repassando aquilo que é de importância. Aqui a gente trabalha na prevenção" (4ACS2). } \\
\text { "Eles falam que nunca vão me esquecer e eu não vou esquecer eles porque eles são minha família. Vivi 18 anos lá (...). Eu } \\
\text { conquistei de um por um, fui conquistando e conquistei o povo inteiro" (2ACS2). } \\
\text { Eu gosto do que eu faço, me sinto bem profissionalmente, eu não pretendo escolher outra profissão por enquanto e ainda } \\
\text { chegar e a pessoa dizer assim: 'Ah, eu consegui isso porque tu me falou, senão não teria ido nem atrás', assim, a gente se } \\
\text { sente maravilhado (...). Eu fico feliz em ser ACS e pretendo ser até quando Deus quiser (1ACS1). }\end{array}$ \\
\hline
\end{tabular}

ENF: enfermeiro.

Fonte: elaboração própria. 


\section{Discussão}

O ACS é um profissional de saúde singular com atribuições gerais na prevenção, promoção e proteção à saúde, e com um papel de mediação social como agente político no território 21,23. Na presente análise identificaram-se componentes do processo de trabalho dos ACS que indicam um escopo ampliado de práticas em municípios rurais remotos, como acompanhamento familiar, cuidados e medidas preventivas individuais, abordagem coletiva/comunitária e atividades administrativas, tendo como atividade principal as visita domiciliar, além de aspectos da qualificação do seu trabalho.

Os ACS têm um papel fundamental em articular ações entre famílias, usuários e serviços de saúde, fortalecendo o vínculo, a comunicação e desenvolvendo escopo amplo de ações de saúde 20,26,29. Nesta pesquisa, o acompanhamento familiar pelos ACS enfatizou a identificação de problemas de saúde e de famílias de maior vulnerabilidade social, por meio da visita domiciliar. Entre os cuidados e as medidas preventivas individuais, os ACS acompanhavam os usuários de programas prioritários de saúde pública, orientavam quanto à atualização vacinal e realizavam, de forma irregular, busca ativa de faltosos. Abordagens comunitárias e integração com outros serviços foram menos observadas pontualmente no acompanhamento do Programa Bolsa Família e PSE. As atividades administrativas concentraram-se na produção no e-SUS APS, orientações sobre o funcionamento da UBS e a comunicação do agendamento de consultas/exames na atenção secundária.

Os ACS de localidades do interior apresentaram escopo de práticas mais abrangente quando comparados aos da sede dos municípios. Uma das principais especificidades das UBS rurais foi uma razoável capacidade de procedimentos individuais e atendimentos de urgência. O trabalho dos ACS incluiu procedimentos clínicos no domicílio e práticas individuais, como aferição de pressão arterial, entrega de medicamentos, distribuição de hipoclorito, atendimento de urgências, apoio no transporte de enfermos, coleta de material para exame de malária, assim como em outros estudos 29,30. Entretanto, um estudo recente problematiza a ampliação das funções dos ACS quanto aos riscos de sobrecarregar o seu processo de trabalho e fragilizar a sua atuação comunitária 26.

Ainda assim, na realidade rural, procedimentos clínicos realizados por ACS são uma necessidade, identificada em países como Canadá e Austrália com programas de saúde rural em seus sistemas nacionais de saúde, dadas as dificuldades de acesso geográfico a profissionais e serviços de saúde 13,31. Um exemplo são os paramédicos comunitários no Canadá, com atuação voltada ao atendimento do idoso, doenças crônicas, promoção da saúde e respostas a emergências 32,33. Contudo, além de contextos socioeconômicos distintos, alerta-se que nesses países os profissionais têm uma formação abrangente para atuação 33 , diferentemente da realidade brasileira onde a formação técnica é insuficiente 34 e ainda há baixos investimentos. Uma recente legislação brasileira (Lei no 13.595/2018 35 - "Ruth Brilhante") aponta para a inclusão de alguns procedimentos clínicos específicos para os ACS com curso técnico, em caráter excepcional.

Os ACS entrevistados, eram ainda, os principais responsáveis pela chegada ao usuário do interior de informação sobre atenção especializada, avisando a marcação da consulta ao usuário, e à equipe o retorno deste ao domicílio, o que sinaliza a contribuição deste profissional para a continuidade do cuidado.

As visitas domiciliares em territórios rurais remotos constituem a principal forma de contato dos serviços de saúde com os usuários, ampliando o acesso aos cuidados. O ACS representa e torna presente o serviço de saúde em localidades onde não é possível estruturar UBS e equipes. Considerando-as imprescindíveis na promoção da saúde e prevenção de agravos na APS 20,36, compreende-se que as visitas domiciliares podem atender a diferentes objetivos, visto a atuação abrangente que o ACS pode desenvolver.

Observaram-se diversas abordagens durante as visitas 36,37 , havendo maior ênfase nas visitas dos ACS a famílias com algum agravo que, em nosso estudo, foi categorizada como visita clínica. Essa característica é resquício de um modelo de atenção centrado no cuidado individual 36,38 e de indução pela gestão dos serviços, quando estabelece prioridades para as visitas domiciliares dos agentes. As visitas domiciliares fazem com que o processo de trabalho do ACS contribua para maior acesso, continuidade do cuidado e formação de vínculos entre profissionais e usuários 23 , com componentes de visita afetiva e melhor compreensão das necessidades das famílias acompanhadas 36,39 , aqui caracterizada como visita preventiva. 
Há, assim, grande potencialidade no trabalho dos ACS, na identificação e desenvolvimento de ações que atendam às necessidades e especificidades da população sob sua responsabilidade 40,41 , e na contribuição para práticas mais democráticas nas relações serviços de saúde/população 42, embora sua atuação seja mais focada em orientações individuais e domiciliares do que coletivas.

A amplitude do processo de trabalho do ACS, expresso nas dimensões da visita domiciliar, reafirma sua imprescindibilidade nas áreas rurais amazônicas e atenta para os riscos de equipes sem ACS, resultados que se contrapõem às proposições da PNAB 2017, que admite equipes sem a presença ou com a redução do número de ACS na ESF 24.

Os ACS desenvolvem um trabalho autônomo, de certa forma isolado (nem sempre possuem equipes ou contato com elas) e pouco supervisionado (ACS rurais vão somente uma vez/mês na UBS ou na sede). Em geral, se relacionam somente com o enfermeiro supervisor e não com toda a equipe, sinalizando baixa integração com a equipe e certa fragmentação nas suas práticas nas visitas domiciliares, similar a outros estudos 23,37 . Tal situação dialoga com a falta de um modelo de organização da APS que incorpore especificidades das áreas remotas e esparsas.

A atuação isolada (geograficamente e em termos de equipe) tem gerado a demanda por desempenho de um papel mais clínico dos ACS rurais, motivando alguns pela formação em técnico de enfermagem, em uma lógica por vezes de atuação substitutiva. Fausto et al. 19 apontam essa dimensão mais técnica do que política no trabalho do ACS presente também nas metrópoles. Mas como potencializar o papel do ACS como "sentinela do cuidado", identificando necessidades e acesso oportuno? É preciso construir propostas que reconheçam as especificidades e moldem o cuidado ofertado em função da realidade rural. Além da integração com a equipe, menor quantidade de população sob a responsabilidade dos ACS rurais deve ser incorporada a políticas e programas da APS para contextos rurais.

A centralidade do processo de trabalho do ACS nas ações no território, junto às famílias e na abordagem individual, acentuada em territórios rurais remotos, foi destacada pelas enfermeiras entrevistadas. Baptistini \& Figueiredo 29 mostram que mesmo com importantes desafios, os ACS não se recolhem nas UBS alegando dificuldades, mas criam alternativas, como trocar a moto pela bicicleta ou ir a pé, e buscam formas diferenciadas de viabilizar a sua prática profissional no território. Diversidade de territórios exige multiplicidade de práticas profissionais.

Os ACS reconheciam a importância de seu trabalho para a UBS e para a comunidade, o que resulta em motivação e satisfação pessoal. Foi comum a percepção de utilidade do seu trabalho, seja impactando as condições de saúde dos usuários, seja no vínculo com as famílias, conforme outros estudos 23,32,41. Como possuíam muitos anos de atuação, o vínculo comunitário foi relatado pelos ACS como um importante fator de motivação. Potencializar e qualificar o seu trabalho no território, sobretudo em áreas rurais, resultaria em melhorias no acesso aos serviços de saúde e continuidade do cuidado à população.

A literatura sugere que as experiências de trabalho do ACS em países de renda média e baixa podem ser bem-sucedidas se os Agentes forem fortemente conectados à comunidade, com papel bem definido e integrados ao sistema formal de saúde 15,43. Abordagens de sucesso são baseadas em necessidades locais, gestão eficaz, treinamento adequado, supervisão, motivação, financiamento e aceitabilidade do programa pelas comunidades. O presente estudo revela que os ACS de áreas rurais necessitam de maior apoio material, de transporte, supervisão, educação permanente e formação técnica estruturada, condizentes com a sua prática profissional, corroborando outras pesquisas 24,44. Insuficiência na formação profissional técnica, relações hierárquicas no trabalho em equipe, falta de apoio e equipamentos são formas de desvalorização do trabalho do ACS 34.

No Brasil, é necessário avançar em um modelo de organização da APS que incorpore especificidades das áreas remotas e esparsas e responda às fragilidades de formação técnica e fragmentação do trabalho do ACS. O trabalho diferenciado dos ACS rurais é um certo arranjo de acesso, consideradas as dificuldades de manter equipes completas e UBS equipadas respondendo às características do território - grandes distâncias e populações esparsas, condição, contudo, que deve ser buscada ainda que incorra em "deseconomia de escala" como apontado por Wakerman et al. 13.

O conjunto ampliado de práticas dos ACS coloca este profissional como um relevante ator para promover cuidados, facilitar o acesso da população rural à rede de atenção à saúde e como um mediador na transformação das práticas de saúde. No contexto rural amazônico não existe atenção básica sem ACS. Famílias sem visita domiciliar do ACS, muitas vezes, são excluídas do direito integral e uni- 
versal à saúde. O ACS mostrou-se como o principal vínculo dos serviços de saúde com a comunidade, muitas vezes o único representante do Estado na localidade, configurando-se como elo real entre a população ribeirinha/rural e o serviço de saúde.

É necessário retirar o ACS rural do lugar de uma atuação substitutiva e de cuidado isolado para valorizá-lo com base em iniciativas de qualificação, apoio e integração à equipe, de forma a ampliar as oportunidades de acesso e de consolidação do direito à saúde. Nesse sentido, são necessárias políticas que reconheçam as especificidades dos territórios e "modelem" o cuidado ofertado em função da realidade dos municípios rurais remotos amazônicos.

\section{Colaboradores}

J. G. Lima, L. Giovanella, M. C. R. Fausto e P. F. Almeida contribuíram na concepção, análise e interpretação dos dados, redação do artigo, revisão e aprovação da versão final.

\section{Informações adicionais}

ORCID: Juliana Gagno Lima (0000-0002-55760002); Lígia Giovanella (0000-0002-6522-545X); Márcia Cristina Rodrigues Fausto (0000-00030746-3684); Patty Fidelis de Almeida (0000-00031676-3574).

\section{Agradecimentos}

Agradecemos a todos os gestores, profissionais da atenção básica e usuários entrevistados, ao grupo da pesquisa atenção primária à saúde em territórios rurais e remotos no Brasil, aos professores e alunos do Instituto de Saúde Coletiva, Universidade Federal do Oeste do Pará que ajudaram na coleta de dados. Ministério da Saúde e Fundação de Amparo à Fiocruz pelo financiamento da pesquisa. L. Giovanella e P. F. Almeida são bolsistas de Produtividade em Pesquisa do Conselho Nacional de Desenvolvimento Científico e Tecnológico (CNPq) e agradecem ao apoio para realização de pesquisas sobre o tema. J. G. Lima foi bolsista de doutorado da Coordenação de Aperfeiçoamento de Pessoal de Nível Superior (CAPES) e agradece o apoio de financiamento.

\section{Referências}

1. McGrail M, Humphreys J. The index of rural access: an innovative integrated approach for measuring primary care access. BMC Health Serv Res 2009; 9:124.

2. Strasser R. Rural health around the world: challenges and solutions. Fam Pract 2003; 20:457-63.

3. Working Party on Rural Practice. Política de qualidade e eficácia dos cuidados de saúde rural. Rev Bras Med Fam Comunidade 2013; 8 Suppl 1:15-24.

4. Grobler L, Marais BJ, Mabunda S. Interventions for increasing the proportion of health professionals practising in rural and other underserved areas. Cochrane Database Syst Rev 2009; (1):CD005314.

5. Chan L, Hart LG, Goodman DC. Geographic access to health care for rural Medicare beneficiaries. J Rural Health 2006; 22:140-6.

6. Scheil-Adlung X; Social Protection Department, International Labour Office. Global evidence on inequities in rural health protection. New data on rural déficits in health coverage for 174 countries. Geneva: International Labour Office; 2015.

7. Alston M, Allan J, Dietsch E, Wilkinson J, Shankar J, Osburn L, et al. Brutal neglect: Australian rural women's access to health services. Rural Remote Health 2006; 6:475.

8. Gruen RL, Weeramanthri TS, Knight SE, Bailie RS. Specialist outreach clinics in primary care and rural hospital settings. Cochrane Database Syst Rev 2004; (1):CD003798.

9. Andrade MV, Noronha KVMS, Menezes RM, Souza MN, Reis CB, Martins DR, et al. Desigualdade socioeconômica no acesso aos serviços de saúde no Brasil: um estudo comparativo entre as regiões brasileiras em 1998 e 2008. Economia Aplicada 2013; 17:623-45. 
10. Macinko J, Dourado I, Aquino R, Bonolo PF, Lima-Costa MF, Medina MG, et al. Major expansion of primary care in Brazil linked to decline in unnecessary hospitalization. Health Aff (Millwood) 2010; 29:2149-60.

11. Bortolotto CC, Loret de Mola C, Tovo-Rodrigues L. Qualidade de vida em adultos de zona rural no Sul do Brasil: estudo de base populacional. Rev Saúde Pública 2018; 52 Suppl 1:4s.

12. Confalonieri UEC. Saúde na Amazônia: um modelo conceitual para a análise de paisagens e doenças. Estud Av 2005; 19:221-36.

13. Wakerman J, Humphreys JS, Wells R, Kuipers P, Entwistle P, Jones J. Primary health care delivery models in rural and remote Australia - a systematic review. BMC Health Serv Res 2008; 8:276.

14. Wong ST, Regan S. Patient perspectives on primary health care in rural communities: effects of geography on access, continuity and efficiency. Rural Remote Health 2009; 9:1142.

15. Pallas SW, Minhas D, Pérez-Escamilla R, Taylor L, Curry L, Bradley EH. Community health workers in low- and middle-income countries: what do we know about scaling up and sustainability? Am J Public Health 2013; 103:e74-82.

16. Giugliani C, Harzheim E, Duncan MS, Duncan BB. Effectiveness of community health workers in Brazil: a systematic review. J Ambul Care Manage 2011; 34:326-38.

17. Lewin S, Munabi-Babigumira S, Glenton C, Daniels K, Bosch-Capblanch X, van Wyk B, et al. Lay health workers in primary and community health care for maternal and child health and the management of infectious diseases. Cochrane Database Syst Rev 2010; (3):CD004015.

18. Viana ALD, Dal Poz MR. A reforma do sistema de saúde no Brasil e o Programa Saúde da Família. Physis (Rio J.) 2005; 15 Suppl:225-64.

19. Fausto MCR, Giovanella L, Mendonça MHM, Almeida PF, Escorel S, Andrade CLT, et al. The work of community health workers in major cities in Brazil: mediation, community action, and health care. J Ambul Care Manage 2011; 34:339-53.

20. Filgueiras AS, Silva ALA. Agente comunitário de saúde: um novo ator no cenário da saúde do Brasil. Physis (Rio J.) 2011; 21:899-916.

21. Giovanella L, Mendonça MHM. Atenção primária à saúde. In: Giovanella L, Escorel S, Lobato, LVC, Noronha JC, Carvalho AI, organizadores. Políticas e sistemas de saúde no Brasil. 2a Ed. Rio de Janeiro: Editora Fiocruz/Centro Brasileiro de Estudos de Saúde; 2012. p. 493545.

22. Santos LPGS, Fracolli LA. O agente comunitário de saúde: possibilidades e limites para a promoção da saúde. Rev Esc Enferm USP 2010; 44:76-83.

23. Alonso CMC, Beguin PD, Duarte FJCM. Trabalho dos agentes comunitários de saúde na Estratégia Saúde da Família: metassíntese. Rev Saúde Pública 2018; 52:14.
24. Morosini MV, Fonseca AF. Os agentes comunitários na atenção primária à saúde no Brasil: inventário de conquistas e desafios. Saúde Debate 2018; 42(spe 1):261-74.

25. Melo EA, Mendonça MHM, Oliveira JR, Andrade GCL. Mudanças na Política Nacional de Atenção Básica: entre retrocessos e desafios. Saúde Debate 2018; 42(spe1):38-51.

26. Silva TL, Soares NA, Lacerda GA, Mesquita JFO, Silveira DC. Política Nacional de Atenção Básica 2017: implicações no trabalho do agente comunitário de saúde. Saúde Debate 2020; 44:58-69.

27. Fausto MCR, Fonseca HMS, Goulart VMP. Atenção primária à saúde em territórios rurais e remotos no Brasil. Projeto de pesquisa. https://cee.fiocruz.br/?q=node/929 (acessado em 21/Out/2019).

28. Bardin L. Análise de conteúdo. Lisboa: Edições 70; 2011.

29. Baptistini RA, Figueiredo TAM. Agente comunitário de saúde: desafios do trabalho na zona rural. Ambiente e Sociedade 2014; 17:53-70.

30. Okwundu CI, Nagpal S, Musekiwa A, Sinclair D. Home- or community-based programmes for treating malaria. Cochrane Database Syst Rev 2013; (5):CD009527.

31. Haggerty JL, Roberge D, Lévesque JF, Gauthier J, Loignon C. An exploration of rural-urban differences in healthcare-seeking trajectories: implications for measures of accessibility. Health Place 2014; 28:92-8.

32. Martin A, O'Meara P, Farmer J. Consumer perspectives of a community paramedicine program in rural Ontario. Aust J Rural Health 2016; 24:278-83.

33. O'Meara P, Ruest M, Stirling C. Community paramedicine: higher education as an enabling factor. Australasian Journal of Paramedicine 2014; 11(2)

34. Nogueira ML. Expressões da precarização no trabalho do agente comunitário de saúde: burocratização e estranhamento do trabalho. Saúde Soc 2019; 28:309-23.

35. Brasil. Lei no 13.595, de 5 de janeiro de 2018. Altera a Lei no 11.350 , de 5 de outubro de 2006, para dispor sobre a reformulação das atribuições, a jornada e as condições de trabalho, o grau de formação profissional, os cursos de formação técnica e continuada e a indenização de transporte dos profissionais Agentes Comunitários de Saúde e Agentes de Combate às Endemias. Diário Oficial da União 2018; 8 jan.

36. Nunes CA, Aquino R, Medina MG, Vilasbôas ALQ, Pinto Júnior EP, Luz LA. Visitas domiciliares no Brasil: características da atividade basilar dos agentes comunitários de saúde. Saúde Debate 2018; 42(n. spe2):127-44.

37. Gaíva MAM, Siqueira VCA. A prática da visita domiciliária pelos profissionais da estratégia saúde da família. Ciênc Cuid Saúde 2011; 10:697-704.

38. Pereira IC, Oliveira MAC. O trabalho do agente comunitário na promoção da saúde: revisão integrativa da literatura. Rev Bras Enferm 2013; 66:412-9. 
39. Mandú ENT, Gaíva MAM, Silva MA, Silva AMN. A visita domiciliária sob o olhar de usuários do programa saúde da família. Texto \& Contexto Enferm 2008; 17:131-40.

40. Lopes RE, Malfitano APS, Palma AM, Furlan PG, Brito EM. Educação e saúde: territórios de responsabilidade, comunidade e demandas sociais. Rev Bras Educ Méd 2012; 36 Suppl 1:18-26.

41. Arboit J, Costa MC, Silva EB, Colomé ICS, Prestes M. Violência doméstica contra mulheres rurais: práticas de cuidado desenvolvidas por ACS. Saúde Soc 2018; 27:506-17.

42. Stotz EN, David HMSL, Bornstein VJ. O agente comunitário de saúde como mediador: uma reflexão na perspectiva da educação popular em saúde. Rev APS 2009; 12:487-97.
43. Costa SM, Araújo FF, Martins LV, Nobre LLR, Araújo FM, Rodrigues CAQ. Agente comunitário de saúde: elemento nuclear das ações em saúde. Ciênc Saúde Colet 2013; 18:2147-56.

44. Oliveira Júnior JG. Agentes comunitários de saúde: fatores restritivos e facilitadores do seu trabalho na Estratégia de Saúde da Família [Dissertação de Mestrado]. Rio de Janeiro: Escola Nacional de Saúde Pública Sergio Arouca, Fundação Oswaldo Cruz; 2012. 


\section{Abstract}

The article aims to analyze the work process for community health agents (ACS in Portuguese) in remote rural municipalities (counties) and identify specificities and contributions to primary healthcare. The qualitative study included 23 interviews with ACS and nurses in the family health teams in five remote rural counties in western Pará State, Brazil. Analysis of the work process for ACS covered two interconnected dimensions: scope of practices and qualification for the work. The scope of practices proved to be comprehensive, involving family follow-up, individual care and preventive measures, collective approach, and administrative activities. Home visits are the main activity by ACS and an important form of contact between health services and the clientele, meeting different objectives of enrollment, care, and information. ACS in remote rural communities, usually the only available health resource, display a broader scope of practices than in the municipal seats, including individual procedures. The qualification of ACS for the work can either enhance or limit the development of their practices and was expressed by the high motivation of the ACS, insufficient supervision and continuing education, and low integration with the larger health team. Policies are needed that acknowledge the specificities and guarantee greater support (materials, transportation, and continuing education) for full development of work by ACS in remote rural communities in the Amazon. The expanded set of practices by ACS suggests that they are relevant actors for providing care, facilitating the population's access to the healthcare network, and as a real link between rural populations and health services in remote rural communities.

Community Health Workers; Rural Health; Primary Health Care

\section{Resumen}

El objetivo del artículo es analizar el proceso de trabajo de los agentes comunitarios de salud (ACS) en municipios rurales remotos e identificar especificidades y contribuciones para el cuidado en la atención primaria en salud. El estudio cualitativo abarcó 23 entrevistas con ACS y enfermeros de los equipos de salud de la familia en cinco municipios rurales remotos del oeste de Pará, Brasil. El análisis del proceso de trabajo de los ACS contempló dos dimensiones interrelacionadas: enfoque de prácticas y cualificación para el trabajo. El enfoque de prácticas se mostró amplio, implicando seguimiento familiar, cuidados y medidas preventivas individuales, abordaje colectivo y actividades administrativas. Las visitas domiciliarias constituyen la principal acción de los ACS e importante forma de contacto de los servicios de salud con usuarios, atendiendo a diferentes objetivos de registro, cuidado o información. Los ACS de localidades rurales remotas, en general el único recurso de salud accesible, presentaron un enfoque de prácticas más amplio que los de la sede de los municipios, con inclusión de procedimientos individuales. La cualificación de los ACS para el trabajo puede potenciar o limitar el desarrollo de sus prácticas y se expresó por la alta motivación de los ACS, insuficiente supervisión y educación permanente y baja integración con el equipo. Se necesitan políticas que reconozcan las especificidades y garanticen mayor apoyo (materiales, transporte y educación permanente) para el pleno desarrollo del trabajo del ACS en los municipios rurales remotos amazónicos. El conjunto ampliado de prácticas de los ACS sugiere que este es un actor relevante para promover cuidados, facilitar el acceso de la población a la red de atención en salud y como vínculo real entre poblaciones rurales y servicios de salud en municipios rurales remotos.

Agentes Comunitarios de Salud; Salud Rural; Atención Primária de Salud
Recebido em 20/Ago/2020

Versão final reapresentada em 25/Nov/2020

Aprovado em 27/Nov/2020 